\title{
Analisis Kesalahan Manusia pada Pengemudi Bus Rapid Transit (BRT) Menggunakan Metode Human Error Assessment and Reduction Technique (HEART) dan Systematic Human Error Reduction and Prediction
}

\author{
Eli Mas'idah ${ }^{1}$, Akhmad Syakhroni', Annisa Ayu Rachmawati ${ }^{1}$ \\ ${ }^{1}$ Program Studi Teknik Industri \\ Universitas Sultan Agung \\ Jl. Raya Kaligawe KM 4 Semarang \\ email :elimasidah@unissula.ac.id \\ doi: https://doi.org/10.31315/opsi.v12i2.3145
}

Received: 16 Oktober 2019; Revised: 28 Oktober 2019; Accepted: 30 December 2019; Available Online: 31 Desember 2019; Published regularly: Desember 2019.

\begin{abstract}
Based on Trans Semarang Bus Rapid Transit (BRT) traffic accident data, it is known that the Trans Semarang BRT still often experiences traffic accidents. Corridor I Trans Semarang with the Mangkang-Penggaron route service area is the Corridor with the highest accident rate compared to other corridors. The high number of accidents occurs because of human error. To solve these problems, in this study using the HEART and SHERPA methods. The HEART method is used to find out what activities constitute critical activities that have the potential to cause accidents and also the probability of human error for each critical activity. Then the SHERPA method is used to strengthen the answers of the HEART method and also to determine recommendations for improvement to fix the existing problem. After conducting research and data processing using the HEART and SHERPA methods, it is known that sub-task 6.4 be careful when driving is a sub-task with the highest probability of human error is 0.549. Furthermore, the subtask was given recommendations for improvement in the form of zero accident socialization to all BRT Corridor I Trans Semarang drivers and to make a particular lane for BRT, especially Corridor I so that the road is separated from other private or public vehicles.
\end{abstract}

Keywords: BRT Corridor I Trans Semarang, HEART, SHERPA

\begin{abstract}
ABSTRAK
Berdasarkan data kecelakaan lalu lintas Bus Rapid Transit (BRT) Trans Semarang, diketahui bahwa BRT Trans Semarang masih sering mengalami kecelakaan lalu lintas. Koridor I Trans Semarang dengan area layanan rute Mangkang-Penggaron merupakan Koridor dengan angka kecelakaan paling tinggi dibandingkan dengan koridor lain. Tingginya angka kecelakaan terjadi karena adanya faktor kesalahan manusia. Untuk menyelesaikan permasalahan tersebut, dalam penelitian ini menggunakan metode HEART dan SHERPA. Metode HEART digunakan untuk mengetahui kegiatan apa saja yang merupakan kegiatan kritis yang berpotensi menyebabkan kecelakaan dan juga probabilitas kesalahan manusia tiap masing - masing kegiatan kritis. Kemudian metode SHERPA digunakan untuk memperkuat jawaban dari metode HEART dan juga untuk menentukan rekomendasi perbaikan untuk memperbaiki permasalahan yang ada. Setelah dilakukan penelitian dan pengolahan data menggunakan metode HEART dan SHERPA diketahui bahwa sub task 6.4 Berhati - hati pada saat mengemudi merupakan sub task dengan probabilitas kesalahan manusia terbesar yaitu 0,549. Selanjutnya pada sub task tersebut diberikan rekomendasi perbaikan berupa sosialisasi zero accident kepada seluruh pengemudi BRT Koridor I Trans Semarang, dan membuat jalur khusus untuk BRT khususnya Koridor I sehingga jalurnya terpisah dari kendaraan pribadi atau umum lainnya.
\end{abstract}

Kata Kunci: BRT Koridor I Trans Semarang, HEART, SHERPA

\section{PENDAHULUAN}

Pemerintah Kota Semarang melalui Dinas Perhubungan telah berhasil mengembangkan Bus Rapid Transit (BRT) sebagai program angkutan umum massal yang lebih nyaman, aman, cepat, murah dan bersifat massal.

Bus Rapid Transit (BRT) Trans Semarang dengan tagline "Terus Berbenah" dan "Semarang Setara" terus berkembang hingga 
saat ini memiliki 7 koridor area layanan. Berdasarkan data kecelakaan lalu lintas Bus Rapid Transit (BRT) Trans Semarang, diketahui bahwa Bus Rapid Transit (BRT) Trans Semarang masih sering mengalami kecelakaan lalu lintas.

Jumlah kecelakaan yang dialami Bus Rapid Transit (BRT) Trans Semarang di tahun 2018 meningkat hampir 5 kali lipat dari tahun 2017. Koridor I Trans Semarang dengan area layanan rute Mangkang-Penggaron yang dipegang oleh PT. Sembilan - Sembilan Cahaya merupakan Koridor dengan angka kecelakaan paling tinggi dibandingkan dengan koridor lain. Pada tahun 2017, Koridor I mengalami 16 kali kecelakaan dan pada tahun 2018 terjadi 73 kali kecelakaan.

Tingginya angka kecelakaan pada Koridor I ini disebabkan oleh adanya kesalahan manusia yang berasal dari pengemudi BRT sendiri dan ada juga yang disebabkan oleh kesalahan orang lain atau pengemudi kendaraan lain.

Oleh karena itu diperlukan adanya sebuah pendekatan guna mengetahui faktor-faktor apa saja yang menjadi penyebab kesalahan manusia atau human error, berapa probabilitas terjadinya kesalahan manusia pada tugas pengemudi dan juga rekomendasi atau solusi perbaikannya untuk meminimalisir terjadinya kesalahan manusia. Pada akhirnya diharapkan dapat menurunkan angka kecelakaan pada Bus Rapid Transit (BRT) Koridor I Trans Semarang.

\section{METODE}

Penelitian dilakukan pada BLU UPTD (Badan Layanan Umum Unit Pelaksana Teknis Dinas) Trans Semarang, Kota Semarang, PT. Sembilan Sembilan Cahaya dan Koridor I Trans Semarang. Objek penelitian yang diamati adalah pengemudi Bus Rapid Transit (BRT) Koridor I Trans Semarang yang memiliki tingkat kecelakaan tinggi. Pengumpulan data dilakukan untuk mengumpulkan data-data yang dibutuhkan dalam pengolahan data untuk memecahkan permasalahan yang telah dirumuskan. Adapun sumber data yang akan dikumpulkan adalah hasil wawancara, data primer yang berupa data perusahaan, data sekunder dari literatur - literatur yang relevan dan pengambilan kuisioner.

\subsection{Human Error Assessment and Reduction Technique (HEART)}

Metode HEART digunakan untuk mengukur kesalahan manusia dalam tugasnya sebagai operator (operator task). Berikut merupakan langkah - langkah yang dilakukan untuk menentukan Human Error Probability dengan menggunakan metode HEART: (a) Mengklasifikasikan jenis tugas/ pekerjaan, (b) Menentukan nilai ketidakandalan dari tugas/ task tersebut, (c) Mengidentifikasi kondisi yang menimbulkan kesalahan / error (EPCs), (d) Menentukan asumsi proporsi kesalahan. Nilai proporsi berkisar antara $0-1(0=$ Low, $1=$ High), (e) Menentukan HEP, Nilai Human Error Probability pada metode HEART didapatkan melalui persamaan:

$\mathrm{HEP}=\mathrm{GC} \times \mathrm{EPCs}^{1} \times \mathrm{EPCs}^{2} \times \mathrm{EPCs}^{3} \mathrm{x} \ldots \mathrm{dst}$

dimana GC adalah Nilai nominal Human Unreliability, EPCs $^{\mathrm{n}}$ adalah Assessed Effect from EPCs, dan EPCs ${ }^{\mathrm{n}}$ merupakan istilah yang digunakan untuk menuliskan hasil dari hubungan antara EPCs dan PoA.

Perhitungan dilakukan dengan menggunakan persamaan sebagai berikut (Bell, J, Holroyd, 2009)

$\mathrm{EPCs}^{\mathrm{n}}=((\mathrm{EPCs}-1) \times \mathrm{PoA}+1)$

dimana EPCs adalah Nilai Error Producing Conditions, dan PoA adalah proporsi dari EPCs

\subsection{Systematic Human Error Reduction and Prediction (SHERPA)}

Metode SHERPA digunakan untuk memperkuat jawaban dari metode HEART dan juga untuk menentukan rekomendasi solusi untuk memperbaiki permasalahan yang ada. Langkah - langkah yang dilakukan dalam penerapan metode SHERPA adalah: (a) Menerapkan analisa ke dalam task yang akan diselidiki, (b) Mengidentifikasi error yang berpotensi besar terjadi dari masing - masing task level dasar, (c) Mengidentifikasi konsekuensi error dan task berikutnya yang dapat mengantisipasi apabila terjadi error, apabila konsekuensinya dianggap kritis (berakibat kerugian yang tidak dapat diterima) maka akan dibuat suatu catatan dan kekritisan dituliskan dalam cara biner. Jika error menyebabkan kecelaaan kerja, maka akan dinotasikan kritis dengan tanda (!) . Apabila tidak menyebabkan kecelakaan kerja, maka akan dinotasikan dengan tanda strip (-). Apabila error tidak pernah muncul maka probabilitasnya low ( 0 ). Apabila error pernah muncul maka probabilitasnya medium $(>0-0,49)$. Jika error tersebut sering terjadi maka probabilitasnya adalah high (0,5 - 1). (Stanton, 2002), (d) Mengisi kuisioner penentuan mode error 
Tabel 1. Tabel SHERPA

\begin{tabular}{|c|c|c|c|c|c|c|c|c|}
\hline $\begin{array}{l}\text { Sub } \\
\text { Task }\end{array}$ & $\begin{array}{l}\text { Kondisi } \\
\text { Penyebab } \\
\text { Error }\end{array}$ & $\begin{array}{l}\text { Kode } \\
\text { Mode } \\
\text { Error }\end{array}$ & $\begin{array}{l}\text { Penjelasan Error } \\
\text { yang Mungkin } \\
\text { Terjadi }\end{array}$ & Akibat & Recovery & Probability & $\begin{array}{l}\text { Tingkat } \\
\text { Kekritisan }\end{array}$ & $\begin{array}{l}\text { Strategi } \\
\text { Perbaikan }\end{array}$ \\
\hline
\end{tabular}

Tabel 2. Klasifikasi tugas atau pekerjaan dalam GTTs

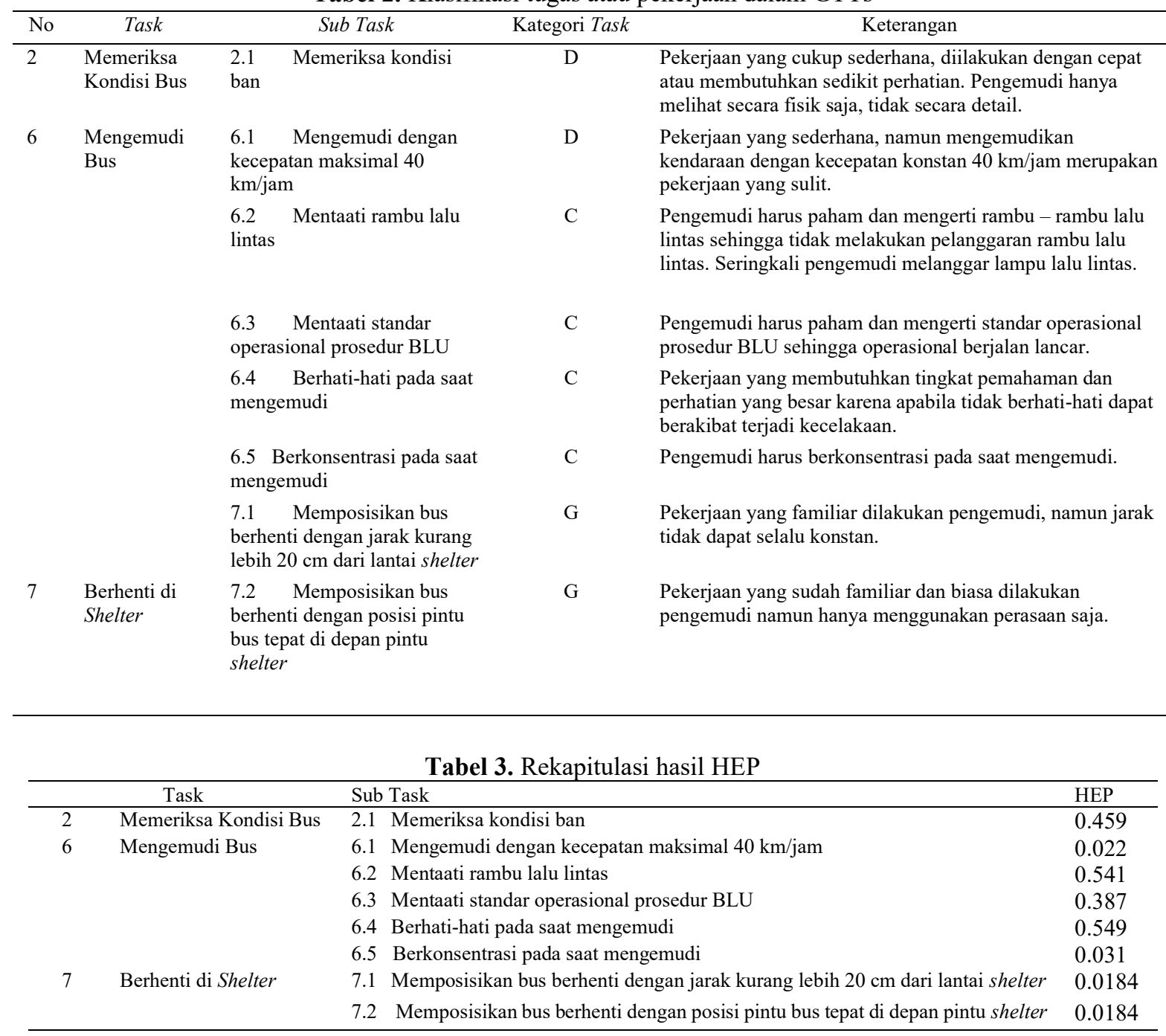

berdasarkan tipe error dalam SHERPA, (e) Metabulasikan error - error tersebut ke dalam tabel SHERPA (Tabel 1).

\section{HASIL DAN PEMBAHASAN}

Berdasarkan tabel hirarki yang telah disusun, diketahui bahwa tugas pengemudi BRT Koridor I Trans Semarang terdiri dari 11 Task dan 41 Sub Task. Uraian tugas pengemudi BRT Koridor I Trans Semarang didapatkan dari hasil wawancara dengan pengemudi dan juga kepala operasional Koridor I Trans Semarang. Setelah menguraikan seluruh pekerjaan pengemudi BRT Koridor I Trans Semarang dalam bentuk tabel, kemudian dibuat struktur pohon HTA untuk mengidentifikasi tugas atau pekerjaan yang dilakukan oleh pengemudi BRT dalam bentuk diagram hirarki.

\subsection{Human Error Assessment And Reduction Technique (HEART)}

Langkah awal dari metode HEART yaitu mengklasifikan tugas atau pekerjaan yang telah didapatkan dari tabel hirarki atau HTA ke dalam 8 pilihan jenis tugas umum yang berbeda (Generic Task Types/ GTTs) mengacu pada Tabel Kategori Umum Metode HEART (Tabel 2). 
Tabel 4. Penentuan nilai EPCs dan APoA

\begin{tabular}{|c|c|c|c|c|c|c|c|c|c|c|}
\hline \multirow{2}{*}{\multicolumn{2}{|c|}{$\begin{array}{c}\text { Task } \\
\text { Sub Task }\end{array}$}} & \multicolumn{9}{|c|}{ Mengemudi Bus } \\
\hline & & \multirow{2}{*}{ Nilai GTTs } & \multicolumn{8}{|c|}{ Nilai EPCs dan APoA } \\
\hline \multirow{3}{*}{2.1} & \multirow{3}{*}{$\begin{array}{l}\text { Memeriksa kondisi } \\
\text { ban }\end{array}$} & & \multirow{3}{*}{ EPCs } & No. EPCs & 13 & & & & & \\
\hline & & \multirow{2}{*}{$\begin{array}{c}\mathrm{D} \\
(0,09)\end{array}$} & & Nilai EPCs & 4 & & & & & \\
\hline & & & & $\mathrm{APoA}$ & 0,7 & & & & & \\
\hline \multirow[t]{3}{*}{6.1} & \multirow{3}{*}{$\begin{array}{l}\text { Mengemudi dengan } \\
\text { kecepatan maksimal } 40 \\
\mathrm{~km} / \text { jam }\end{array}$} & \multirow{3}{*}{$\begin{array}{c}\mathrm{D} \\
(0,09)\end{array}$} & \multirow{3}{*}{ EPCs } & No. EPCs & 6 & 32 & 34 & & & \\
\hline & & & & Nilai EPCs & 8 & 1,2 & 1,1 & & & \\
\hline & & & & $\mathrm{APoA}$ & 0,2 & 0,2 & 0,2 & & & \\
\hline \multirow[t]{3}{*}{6.2} & Mentaati rambu lalu & \multirow{3}{*}{$\begin{array}{c}\mathrm{C} \\
(0,16)\end{array}$} & \multirow{3}{*}{ EPCs } & No. EPCs & 2 & 31 & & & & \\
\hline & lintas & & & Nilai EPCs & 11 & 1,2 & & & & \\
\hline & & & & $\mathrm{APoA}$ & 0,3 & 0,3 & & & & \\
\hline \multirow[t]{3}{*}{6.3} & Mentaati standar & \multirow{3}{*}{$\begin{array}{c}\mathrm{C} \\
(0,16)\end{array}$} & \multirow{3}{*}{ EPCs } & No. EPCs & 6 & 21 & 31 & & & \\
\hline & operasional prosedur & & & Nilai EPCs & 8 & 2 & 1,2 & & & \\
\hline & BLU & & & APoA & 0,2 & 0,2 & 0,2 & & & \\
\hline \multirow{3}{*}{6.4} & \multirow{3}{*}{$\begin{array}{l}\text { Berhati-hati pada saat } \\
\text { mengemudi }\end{array}$} & \multirow{3}{*}{$\begin{array}{c}\mathrm{C} \\
(0,16)\end{array}$} & \multirow{3}{*}{ EPCs } & No. EPCs & 4 & 6 & 28 & 29 & 33 & 34 \\
\hline & & & & Nilai EPCs & 9 & 8 & 1,4 & 1,3 & 1,15 & 1,1 \\
\hline & & & & APoA & 0,8 & 0,8 & 0,8 & 0,8 & 0,8 & 0,8 \\
\hline \multirow{3}{*}{6.5} & \multirow{3}{*}{$\begin{array}{l}\text { Berkonsentrasi pada saat } \\
\text { mengemudi }\end{array}$} & \multirow{3}{*}{$\begin{array}{c}\mathrm{C} \\
(0,16)\end{array}$} & \multirow{3}{*}{ EPCs } & No. EPCs & 4 & 27 & 28 & 29 & 33 & 34 \\
\hline & & & & Nilai EPCs & 9 & 1,4 & 1,4 & 1,3 & 1,15 & 1,1 \\
\hline & & & & $\mathrm{APoA}$ & 0,8 & 0,8 & 0,8 & 0,8 & 0,8 & 0,8 \\
\hline \multirow{3}{*}{7.1} & \multirow{3}{*}{$\begin{array}{l}\text { Memposisikan bus } \\
\text { berhenti dengan jarak } \\
\text { kurang lebih } 20 \mathrm{~cm} \\
\text { dari lantai shelter }\end{array}$} & \multirow{3}{*}{$\begin{array}{c}\mathrm{G} \\
(0,0004)\end{array}$} & \multirow{3}{*}{ EPCs } & No. EPCs & 2 & 6 & 13 & 33 & & \\
\hline & & & & Nilai EPCs & 11 & 8 & 4 & 1,15 & & \\
\hline & & & & APoA & 0,1 & 0,1 & 0,1 & 0,1 & & \\
\hline \multirow{3}{*}{7.2} & & & EPCs & No. EPCs & 2 & 6 & 13 & 33 & & \\
\hline & Memposisikan bus & G & EPCS & Nilai EPCs & 11 & 8 & 4 & 1,15 & & \\
\hline & $\begin{array}{l}\text { pintu bus tepat di } \\
\text { depan pintu shelter }\end{array}$ & $(0,0004)$ & & APoA & 0,1 & 0,1 & 0,1 & 0,1 & & \\
\hline
\end{tabular}

Tabel 5. Metode SHERPA

\begin{tabular}{|c|c|c|c|c|c|c|c|c|}
\hline Sub Task & Kondisi penyebab Error & $\begin{array}{l}\text { Kode } \\
\text { Mode } \\
\text { Error }\end{array}$ & $\begin{array}{l}\text { Penjelasan error } \\
\text { yang mungkin } \\
\text { terjadi }\end{array}$ & Atribut & Recovery & Probability & $\begin{array}{l}\text { Tingkat } \\
\text { kekritisan }\end{array}$ & Strategi perbaikan \\
\hline $\begin{array}{l}6.2 \\
\text { Mentaati } \\
\text { rambu lalu } \\
\text { lintas }\end{array}$ & $\begin{array}{l}\text { 1. Kurang atau tidak } \\
\text { tersedianya waktu dalam } \\
\text { melakukan pengecekan } \\
\text { ulang ketika melakukan } \\
\text { setting/mendeteksi } \\
\text { kesalahan/terburu-buru } \\
\text { dalam melakukan } \\
\text { pekerjaan } \\
\text { 2. Tingkat kedisiplinan } \\
\text { rendah }\end{array}$ & A8 & $\begin{array}{l}\text { 1. Pengemudi } \\
\text { menerobos } \\
\text { lampu lalu } \\
\text { lintas } \\
\text { 2. Pengemudi } \\
\text { tidak melihat } \\
\text { atau } \\
\text { melanggar } \\
\text { rambu lalu- } \\
\text { lintas }\end{array}$ & $\begin{array}{l}\text { 1. Dapat } \\
\text { mengakibatkan } \\
\text { kecelakaan } \\
\text { 2. Dapat } \\
\text { membahayan } \\
\text { pengendara } \\
\text { lain } \\
\text { 3. Dapat } \\
\text { mengganggu } \\
\text { kelancaran lalu } \\
\text { lintas }\end{array}$ & $\begin{array}{l}\text { Tidak } \\
\text { dapat } \\
\text { dilakukan } \\
\text { recovery }\end{array}$ & $\begin{array}{l}0,541 \\
(\text { High })\end{array}$ & ! & $\begin{array}{l}\text { 1. Dilakukan sosialisasi } \\
\text { zero accident kepada } \\
\text { seluruh pengemudi BRT } \\
\text { Koridor I rans Semarang } \\
\text { 2. Dilakukan sosialisasi } \\
\text { pemahaman rambu lalu } \\
\text { lintas dan pentingnya } \\
\text { mentaati rambu lalu } \\
\text { lintas }\end{array}$ \\
\hline $\begin{array}{l}6.4 \\
\text { Berhati- } \\
\text { hati pada } \\
\text { saat } \\
\text { mengemudi }\end{array}$ & $\begin{array}{l}\text { 1. Adanya gangguan- } \\
\text { gangguan yang sangat } \\
\text { mudah mempengaruhi } \\
\text { 2. } \begin{array}{l}\text { Ketidaksesuaian SOP } \\
\text { dengan kenyataan }\end{array} \\
\text { lapangan } \\
\text { 3. Terganggunya tingkat } \\
\text { emosional akibat stress } \\
\text { kerja } \\
\text { Tingkat stress secara } \\
\text { emosional } \\
\text { 5. Lingkungan yang buruk } \\
\text { atau tidak mendukung } \\
\text { 6. Siklus yang berulang- } \\
\text { ulang yang tinggi dari } \\
\text { pekerjaan dengan beban } \\
\text { kerja bermental rendah }\end{array}$ & A1 & $\begin{array}{l}\text { 1. Pengemudi } \\
\text { mengemudikan } \\
\text { bus dengan } \\
\text { kurang hati-hati } \\
\text { karena } \\
\text { mengalami } \\
\text { kelelahan } \\
\text { mental } \\
\text { 2. Jarak pandang } \\
\text { yang terbatas, } \\
\text { sering membuat } \\
\text { pengemudi } \\
\text { tidak bisa } \\
\text { melihat } \\
\text { kendaraan lain } \\
\text { 3. Adanya kondisi } \\
\text { berbahaya tak } \\
\text { terduga yang } \\
\text { tiba-tiba terjadi }\end{array}$ & $\begin{array}{l}\text { 1. Dapat } \\
\text { mengakibatkan } \\
\text { kecelakaan } \\
\text { 2. Dapat } \\
\text { membahayakan } \\
\text { pengendara } \\
\text { lain }\end{array}$ & $\begin{array}{l}\text { Tidak } \\
\text { dapat } \\
\text { dilakukan } \\
\text { recovery }\end{array}$ & $\begin{array}{l}0,549 \\
\text { (High) }\end{array}$ & ! & $\begin{array}{l}\text { 1. Dilakukan sosialisasi zero } \\
\text { accident kepada seluruh } \\
\text { pengemudi BRT Koridor I } \\
\text { rans Semarang } \\
\text { 2. Membuat jalur khusus } \\
\text { untuk BRT khususnya } \\
\text { Koridor I sehingga } \\
\text { jalurnya terpisah dari } \\
\text { kendaraan pribadi atau } \\
\text { umum lainnya }\end{array}$ \\
\hline
\end{tabular}

Delapan sub task ini selanjutnya akan dilakukan analisa dan perhitungan nilai Human Error Probablity (HEP) dengan melakukan penentuan nilai Error Producing Conditions (EPCs) dan Assesses Proportion of Affect (ApoA) terlebih dahulu serta Perhitungan Nilai Probabilitas Kesalahan Manusia atau HEP (Tabel 4) tersebut, kemudian dilakukan perhitungan efek error yang terjadi melalui proporsi EPCs (Tabel 3)

\subsection{Systematic Human Error Reduction and Prediction Approach (SHERPA)}

Berdasarkan GTTs, EPCs dan APoA setelah dilakukan tabulasi metode SHERPA diketahui, terdapat 2 sub task yang termasuk 
dalam sub task dengan probabilitas kesalahan manusia yang tinggi atau High yaitu sub task 6.2 Mentaati rambu lalu lintas dan sub task 6.4 Berhati - hati pada saat mengemudi (Tabel 5)

\section{KESIMPULAN}

Berdasarkan penelitian yang sudah dilakukan pada pengemudi BRT Koridor I Trans Semarang, maka dapat diambil kesimpulan bahwa Metode HEART merupakan metode yang digunakan untuk menentukan dan menghitung tingkat probabilitas kesalahan manusia. Setelah dilakukan perhitungan didapatkan sub task 6.4 Berhati - hati pada saat mengemudi merupakan sub task dengan nilai HEP terbesar yaitu 0,549.

Rekomendasi perbaikan yang diberikan yaitu: (a) Pemasangan alarm pengingat ketika kecepatan bus melebihi kecepatan maksimal. (b)Pemeriksaan kondisi ban tidak hanya dilihat secara kasat mata namun juga secara detail dan disertai formulir pemeriksaan awal keberangkatan, (c) Dilakukan sosialisasi zero accident kepada seluruh pengemudi BRT Koridor I Trans Semarang dengan mengumpulkan seluruh pengemudi dan mendatangkan pihak terkait seperti Dinas Perhubungan atau Kepolisian bagian Lalu Lintas untuk memberikan materi bagaimana mengemudi yang baik dan aman di jalan raya sehingga dapat mewujudkan zero accident, (d) Dilakukan sosialisasi pemahaman rambu lalu lintas dan pentingnya mentaati rambu lalu lintas, (e) Melakukan briefing bulanan secara rutin untuk menekankan pengemudi agar mentaati SOP BLU, (f) Membuat jalur khusus untuk BRT khususnya Koridor I sehingga jalurnya terpisah dari kendaraan pribadi atau umum lainnya, (g) Pemberian garis batas berhenti bus pada seluruh shelter BRT Trans Semarang, (h) Memberikan tunjangan kepada pengemudi, berdasarkan Keputusan Direktur Jenderal Perhubungan Darat Nomor : SK.687/AJ.206/DRJD/2002 Tentang Pedoman Teknis Penyelenggraan Angkutan Penumpang Umum Diwilayah Perkotaan Dalam Trayek Tetap Dan Teratur, awak atau pengemudi bus berhak mendapatkan tunjangan berupa perawatan kesehatan, baju dinas dan asuransi kecelakaan. Diharapkan dari adanya tunjangan tersebut dapat membuat pengemudi merasa tenang dan senang dalam bekerja sehingga dapat berkonsentrasi penuh dalam mengemudi.

\section{DAFTAR PUSTAKA}

A. Alatas, H. (2014). Identifikasi Human Eror Pada Proses Produksi Cassava Chips Dengan Menggunakan Metode Sherpa Dan Heart Di PT. Indofood Fritolay Makmur. Jurnal PASTI, XI(1), 98-110.

Adi, Nugroho, G. (2011). Analisis Tingkat Keandalan Pada Sopir Dengan Metode HEART Human Assessment and Reduction Technique) (Studi Kasus : PO Sumber Alam Purworejo). 66.035; Laporan Tugas Akhir Teknik Industri, UNDIP.

Ansori, N. dan M. (2013). Sistem Perawatan Terpadu. Yogyakarta: Graha Ilmu.

Bell, J., \& Holroyd, J. (2009). Review of Human Reliability Assessment Methods. Health \& Safety Laboratory, 78.

Dhillon, B. S. (2007). Reliability, Quality, adn Safety Engineers. CRC Press LLC.

Irwansyah Atmaja, M. (2018). Human Error Analysis Pada Bagian UPH Assembly Sofa Departemen UPHOLSTERY Menggunakan Metode Human Error ( HEART ) DAN Systematic Human Error Reduction AND Prediction ( SHERPA ). Laporan Tugas Akhir Teknik Industri, UNISSULA.

Masita, M. (2017). Analisa Human Error Dengan Metode SHERPA dan HEART Pada Proses Produksi Batik Cap (Studi Kasus: UKM Batik Cap Supriyarso Kampoeng Batik Laweyan). Laporan Tugas Akhir Teknik Industri, UMS.

Mesiter, V. (1997). Human Factors in Engineering and Design. New Jersey: Mc Graw-Hill, Inc.

Nurhayati, R., Ma, I., \& Hartanti, R. I. (2017). Penilaian Human Error Probability dengan Metode Human Error Assessment and Reduction Technique ( HEART ). Jurnal Pustaka Kesehatan, Vol. 5, (No. 3), 5(3), 565-571.

Peraturan Pemerintah NO. 43. (1993). Tentang Prasana dan Lalu Lintas Jalan, 1.

RI, D. P. SK.687/AJ.206/DRJD/2002 Tentang Pedoman Teknis Penyelenggraan Angkutan Penumpang Umum Diwilayah Perkotaan Dalam Trayek Tetap Dan Teratur Direktur Jenderal Perhubungan Darat.

Stanton, W, J. (2002). Prinsip Pemasaran. Jakarta: Penerbit Erlangga. 
Sutalaksana, I. Z. (1979). Teknik Tata Cara Kerja. Institut Teknologi Bandung.

Whittingham, R, B. (2004). The Blame Machine: Why Human Error Causes. London: Elsevier Butterworth Heinemann.

Miller, G., Pawloski, J., \& Standrigde, C., 2010, A Case Study Of Lean, Sustainable Manufacturing, Journal of Industrial
Engineering and Management, Vol 3, No. 1, pp: 11-32.

Rangkuti, F., 2005, Analisis SWOT Teknik Membedah Kasus Bisnis, PT Gramedia Pustaka Utama, Jakarta.

Wilson, L, 2010, How to Implement Lean Manufacturing. The McGraw-Hill Companies, Inc., United States. 